\title{
A Study on the Purchase Behavior of Buying Children Mobile Phones
}

\author{
Wen-Ke Liang ${ }^{1}$, Yu-Han $\mathbf{L i}^{2}$ \\ ${ }^{1}$ Department of International Business, Southern Taiwan University of Science and Technology, Tainan, Taiwan \\ ${ }^{2}$ Department of Applied English, Southern Taiwan University of Science and Technology, Tainan, Taiwan
}

Email address:

wenke@stust.edu.tw (Wen-Ke Liang)

\section{To cite this article:}

Wen-Ke Liang, Li Yu-Han. A Study on the Purchase Behavior of Buying Children Mobile Phones. Psychology and Behavioral Sciences. Vol. 6, No. 1, 2017, pp. 9-15. doi: 10.11648/j.pbs.20170601.12

Received: October 29, 2017; Accepted: November 24, 2017; Published: March 18, 2017

\begin{abstract}
This study is aimed to explore what factors may affect parents when they want to buy mobile phones for children, and discuss the motivation of parents on buying mobile phones for children. After understanding the purchase factors and the purchase motivation of parents, this study can attempt to know further about parents' purchasing behavior and their purchase decision-making. The researcher of this study used in-depth interviews to interview with forty respondents which contained ten pairs of parents and children who already have a mobile phone and ten pairs of parents and children who do not have a mobile phone now. Based on the results of interviews, the primary purchase factor is the price of mobile phones. Parents think that the price of a mobile phone has to be within reasonable limits. The secondary purchase factor is the function of mobile phones. Parents hope that the functions for children to use can be as simple as possible. Besides, parents also hope that there can be some limit and learning functions for children to use. The main motivation of parents on buying mobile phones for children is the convenience of contact. Parents think that when children really have the need to use a mobile phone, they will consider buying one for children.
\end{abstract}

Keywords: Mobile Phone, Purchasing Behavior, Purchase Decision-Making

\section{Introduction}

Children are a highly regarded group in today's society, and they are also so loved by their parents. Thus, mobile phones are an important medium for parents to keep in touch with their children. As the time changes, there are more and more dual-earner families. The probability of a child staying at home alone may increase a lot. Sometimes parents cannot know exactly where their children are. In this case, parents will consider buying a mobile phone for children, or giving an old one to them. Although some parents would like to allow their children to have a mobile phone, they may still need to consider many factors before buying a mobile phone for their children. For example, we can predict that most children are so addicted to mobile phones now. Children can spend all the time using or playing their mobile phones [1]. If children do not establish a good concept of using a mobile phone, they may overuse it. Consequently, some parents do not agree and allow their children to have a mobile phone, because a mobile phone may change children's lifestyles. In fact, we do not know fully what parents' actual opinions are and what factors they will think about when they want to buy a mobile phone for their children.

On the other hand, mobile phones, especially smart phones, have a wide variety of functions now. It can have a large attraction for children. Using the Internet may be the most popular function for children who want a smart phone, because they can instantly connect to websites they like or download many applications from app stores. In addition, most children like to use their mobile phones to play games. Sometimes they may only focus on mobile phones, and forget to do many things that they have to do. Therefore, we still need to understand what functions parents will allow their children to use or what functions parents do not allow their children to use. We also do not know clearly children's current situations of using mobile phones. Some parents may concern over their children's use of mobile phones. If we can realize all situations, we will find out what factors that may affect parents buying a mobile phone for their children in the end. 
The purpose of this study is to investigate the present situation of parents' purchase behavior of buying children mobile phones. This study attempts to find out what factors that parents may consider when they are willing to buy children mobile phones. Moreover, this study also aims to understand parents' motives and know their needs of children's mobile phones. The researcher of this study will conduct interviews with parents and children to complete this investigation. The researcher will design the interview guide first and do the semi-structured interviews with respondents. The scope of this study will be aimed on parents and children who are the fifth and sixth grade students in Tainan. In order to compare parents who are willing to buy mobile phones and who do not want to buy mobile phones for children, the researcher decides to choose ten children who already have a mobile phone and ten children who still do not have a mobile phone. After selecting twenty children as respondents, the researcher will have interviews with them and their parents. Therefore, a total of forty people are expected to be interviewed.

\section{Literature Review}

\subsection{The Proportion of Children Using Mobile Phones}

With the rapid development of technology, mobile phones have become an essential communication tool for people. Based on the report of the Group eSpeciale Mobile Association (GSMA) and the Mobile Society Research Institute in 2012, 65 percent of all children surveyed presently use a mobile phone [2]. In 2009, Fubon Cultural and Educational Foundation(FCEF) expressed that having a mobile phone has become an inevitable trend for young people, and the possibility of younger children owning their mobile phones is also becoming significant since mobile phones are so popular now [3]. Researchers expressed that parents and young people thought that mobile phones are a crucial and important feature in today's modern lives due to the convenience, a way to manage family and social lives [4].

In the research of national children media usage supported by FCEF in 2009, the result showed that 29 percent of children had their own mobile phones in Taiwan and among these 29 percent of children, 53.1 percent of them already had their first mobile before ten years old. The Child Welfare League Foundation (CWLF) in 2011 indicated that the situation of children using mobile phones is quite common in Taiwan these days. From the survey of children's uses of mobile phones in Taiwan in 2011, CWLF found that 55.3 percent of the fifth and sixth grade students used mobile phones [5]. The survey also showed that 1.6 percent of children started using mobile phones in the kindergartens, and 6.8 percent of children began to use mobile phones at the first and second grade in the elementary schools. Thus, we can know that the age of children is significantly getting younger and younger in mobile phones ownership from this survey. Most parents connect with their children by using mobile phones. Consequently, Mobile phones could be a form of social control [6] [7]. Parents will worry about the safety of their children, so that they use mobile phones as a way to keep in touch with children. Children from age eight to twelve would show a high degree of interest in the new technology and they are also fascinated by the complexity of the technology [8] [9]. Therefore, children can spend a lot of time on new technology products. From the report of national children media usage supported by FCEF in 2009, there are three major functions that elementary school students usually like to use with mobile phones, including listening to music, talking on the phone and playing built-in games, and they usually use mobile phones to contact their family, classmates and friends. On the other hand, based on the survey of children's uses of mobile phones in Taiwan conducted by CWLF in 2011, 57.1 percent of children talk on the mobile phones less than five minutes a day. Instead, children use mobile phones to listen to music $(77.1 \%)$, take pictures $(69.5 \%)$, play games $(63.6 \%)$, send text messages $(61.9 \%)$, record a video (44\%), download music or files(22.3\%) and surf the Internet $(11.2 \%)$. It is clear that children pay more intention to the functions of entertainment on mobile phones.

\subsection{Relationship Between Purchase Factors and Purchase Behavior}

All internal individual factors and external environmental factors can influence consumers' purchase behaviors and their purchase decisions. Due to too many influencing factors, Cheng [10] had concluded that internal individual factors contain motivation, perception, attitude, learning and personality; external environmental factors contain individuals, families, groups, social classes and cultures. However, Guiltinan [11] had proposed specifically that product attributes are the key factors affecting consumers' purchase decisions from the result of his study; these product attributes factors include price, brand, word-of-mouth, compatibility and comparative advantage. Armstrong and Kotler [12] classified some factors that may affect consumers' purchase behaviors as following:

(a) Cultural factors: These factors include culture, subculture and social classes.

(b) Social factors: These factors consist of families, groups, roles and status.

(c) Personal factors: These factors contain age, occupation, economic status, lifestyle, personality or values.

(d) Psychological factors: These factors include motivation, cognition, attitudes and learning.

On the part of some studies on purchase factors, Kao [13] compiled several factors that influence consumers to evaluate on smart phones from product attributes. These factors consist of brand style, service marketing, convenience, function expansion, surrounding links, multimedia applications and price. Huang [14] examined consumers' intentions and motives for purchasing camera mobile phones, and the result showed that most factors are related to the product attributes such as price, after-sales service, Internet service, brand, mobile phone's style, ring, data storage capacity, warranty period and so on [15]. Chang [16] 
investigated consumers' needs for camera mobile phones, the outcome of the survey indicated that when consumers want to buy mobile phones, they will think about the warranty period, maintenance service, photography function, design of mobile phones, built-in game, Internet function and so on. According to the survey of the situation of mobile phone usage in Taiwan that was conducted by Insight Xplorer in 2005 , most consumers thought that the price is the primary evaluating factor when they want to buy mobile phones [17], and other secondary evaluating factors are the function, quality, appearance or weight of mobile phones. Lan [18] found that consumers will consider all functions and the brand image of products in his study on the bicycle industry.

Based on the above studies, there are many factors that consumers will consider when they want to purchase. Most of the factors are related to the product attributes. In addition, it is obvious that the price and the function of mobile phones have been identified as two most important factors that will affect consumers purchasing mobile phones. Christensen [19] pointed out that the pace of technology's development is often beyond the needs of the market and consumers. Therefore, product attributes may become main purchase factors for consumers when they choose a product to buy. For this study, the researcher wants to investigate what purchase factors that parents may consider when they are willing to buy mobile phones for their children.

\subsection{Relationship Between Purchase Motivation and Purchase Behavior}

This part discusses about some studies that are related to purchase motivation and purchase behavior. From the result of examining the purchase motivation in TV shopping channel, Pei [20] noted that when making a purchase, consumers think that products should meet their demands, and the price should be fair to them [21]. In the study of purchasing decision of domestic readers of best-sellers, Tsai [22] confirmed that consumers' motivation will affect their purchase decisions. He indicated that the consumers' motives of sending books to others, having their own books and changing their lives are highly related with their purchase decisions. After investigating purchase behavior in selecting male facial skin care products from female consumers, Chiu [23] pointed out that female consumers pay more attention to the functional products when they choose male facial skin care products for elders and spouses. Hsu [24] expressed that the conspicuous value is one of the main variables to explain the purchase motivation of NBA stars endorsement shoes. Chung [25] classified four dimensions of motivation that will influence consumers' purchase behavior, including food safety, brand image, reasonable price and recommended by friends and relatives in her research on an investigation into consumers of bubble tea.

Based on the above studies, we can know that consumers' purchase motivation can be diverse. People may have a lot of needs, so that they will have different motives [26]. Motivation is the driving force of meeting the demand of consumers [27]. Therefore, motivation may affect consumers' purchase behaviors. This study is aimed to examine parents' motivation of buying mobile phones for their children. These motives will influence parents' purchase decisions and further have an impact on their purchase behaviors.

\section{Methodology}

\subsection{Research Framework of this Research}

Based on research purposes of this study, the main direction of the research framework is to find out factors that parents may consider when they want to buy a mobile phone for their children and understand parents' motivation of buying children mobile phones by the in-depth interview method. Then the results can help to understand further the purchase behavior of parents on buying mobile phones for their children. The research framework of this study is shown in Figure 1.

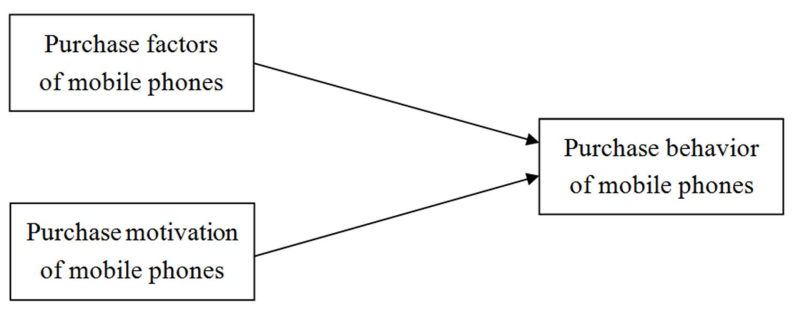

Figure 1. The research framework of this study.

\subsection{In-Depth Interviews}

In-depth interviews are useful tools to design and evaluate an expanded program in the qualitative research. In-depth interviews can help interviewers to explore more deeply the opinions and feelings of the respondents on a certain topic [28]. The major advantage of in-depth interviews is that interviewers can collect more detailed information from the respondents. Besides, in-depth interviews can offer more comfortable atmosphere for the respondents to have a conversation with interviewers [29]. In an in-depth interview, the interviewer only interacts with one respondent at a time and follows the interview guide to discuss the main subject. In addition, the interviewer can also think about more appropriate questions based on the actual situations of different respondents within the interview and the interaction between the interviewer and respondent may easily affect the results of the interview [30]. Babbie [31] indicated that in-depth interviews are used to truly understand the respondents' explanations for their experiences and lives. Therefore, the researcher of this study decided to use the in-depth interview method due to obtaining the complete data collection from the respondents.

\subsection{Participants}

Due to the difficulty of collecting data, the researcher of current study decided to use the purposive sampling technique. Purposive sampling is also referred to purposeful sampling or non-probability sampling. It means that the researcher can select certain cases for a particular purpose 
[32]. Therefore, the researcher chose particular respondents based on the purpose of this study. Thanks to the region and time limits, the researcher simply focused on the participants who live in Tainan. Moreover, due to the ability of expression and comprehension, the researcher has decided to select the fifth and sixth grade students as participants. In the decision-making process, the researcher believes that parents will consult with children about children's views on mobile phones and then make the final purchase decision. Consequently, in order to compare parents who are willing to buy mobile phones and who do not want to buy mobile phones for children, the researcher decided to select ten children who already have a mobile phone and ten children who still do not have a mobile phone. Firstly, the researcher began to find some children who are the fifth and sixth grade students in the neighborhood. Then the researcher asked teachers who work in the Kun-Shan elementary school to recommend some students. After electing twenty children, the researcher started to have interviews with them and their parents. The researcher has completed all interviews from April to June in 2013. Totally there were forty participants that consisted of twenty pairs of parents and children. Among these twenty pairs of parents and children, there were eighteen mothers, two fathers, seven boy students and thirteen girl students. After finishing all interviews, all respondents are listed as the Table 1. Due to the protection of respondents' basic background information, the respondents of parents would be named from $\mathrm{A}$ to $\mathrm{T}$ in capital letters and their children would be named from $\mathrm{A}$ to $\mathrm{T}$ in small letters.

Table 1. The Information of Respondents.

\begin{tabular}{|c|c|c|c|c|c|}
\hline & Parent & Child & Child's grade & Child's elementary school & Interview date \\
\hline Pair 1 & A & a & sixth grade & Kun-Shan & 2013.4 .6 \\
\hline Pair 2 & B & $\mathrm{b}$ & fifth grade & Kun-Shan & 2013.4 .7 \\
\hline Pair 3 & $\mathrm{C}$ & $\mathrm{c}$ & sixth grade & Kun-Shan & 2013.4 .11 \\
\hline Pair 5 (०) & $\mathrm{E}$ & $\mathrm{e}$ & sixth grade & Kun-Shan & 2013.5 .5 \\
\hline Pair 6 (०) & $\mathrm{F}$ & $\mathrm{f}$ & sixth grade & Kun-Shan & 2013.5 .10 \\
\hline Pair 7 & G & $\mathrm{g}$ & fifth grade & Yu-Wen & 2013.5 .11 \\
\hline Pair 9 (०) & I & $\mathrm{i}$ & sixth grade & Kun-Shan & 2013.5.16 \\
\hline Pair $10(\circ)$ & $\mathrm{J}$ & $\mathrm{j}$ & sixth grade & Kun-Shan & 2013.5 .17 \\
\hline Pair 11 (०) & $\mathrm{K}$ & $\mathrm{k}$ & sixth grade & Kun-Shan & 2013.5 .17 \\
\hline Pair 12 & $\mathrm{~L}$ & 1 & fifth grade & Yong-Kang & 2013.5.18 \\
\hline Pair 13 & M & $\mathrm{m}$ & fifth grade & Kun-Shan & 2013.5 .20 \\
\hline Pair 14 (०) & $\mathrm{N}$ & $\mathrm{n}$ & sixth grade & Kun-Shan & 2013.5 .20 \\
\hline Pair 15 (०) & $\mathrm{O}$ & o & sixth grade & Cheng-Hsing & 2013.6 .1 \\
\hline Pair 16 & $\mathrm{P}$ & $\mathrm{p}$ & fifth grade & Kun-Shan & 2013.6 .7 \\
\hline Pair 18 & $\mathrm{R}$ & $\mathrm{r}$ & fifth grade & Kun-Shan & 2013.6 .25 \\
\hline Pair 19 (०) & $\mathrm{S}$ & $\mathrm{s}$ & fifth grade & Kun-Shan & 2013.6 .26 \\
\hline Pair $20(\circ)$ & $\mathrm{T}$ & $\mathrm{t}$ & fifth grade & Kun-Shan & 2013.6 .27 \\
\hline
\end{tabular}

\section{Data Analysis and Result}

Based on the interview guide, there are eight main questions. The former four questions are aimed to understand parents' opinions on buying children mobile phones. The latter four questions focus on investigating children's opinions on mobile phones. Respondents would be named by the respondents' code as the Table 1 .

\subsection{What Are Parents' Opinions of Their Children Having a Mobile Phone?}

Twelve parents indicated that there is no need for children to use mobile phones now. Children lack of self-control. If they have their own mobile phones, children may indulge in the games of mobile phones. Besides, mobile phones may affect children's schoolwork and mobile phones are also no good to children's eyes. If children want to contact parents in school, they can just ask teachers to help. Therefore, some parents said that children do not have many opportunities to use a mobile phone at this stage. A parent said that "I don't think that children can have their mobile phones now. There is no need for children to use mobile phones. It is just a trend." Another parent pointed out that "Mobile phones are just tools for children to play games. I do not think that it is appropriate for children to have a mobile phone."

\subsection{What Factors Will Parents Consider When Deciding to Purchase a Mobile Phone for Their Children?}

Based on the answers of twenty parents, the functions that parents hope to have in children's mobile phones can be classified as following:

I. General functions: Most parents think that general functions that include making a call, sending a text message, taking a picture and listening to music can be enough for a child to use.

II. Limit functions setting: Some parents hope that there can be some limit functions inside a mobile phone for children, such as the restriction of call duration and the limit of Internet access duration.

III.The function of Global Positioning System (GPS): Some parents believe that a mobile phone with GPS 
function can help parents to know where their children are. It is safer to have a mobile phone to protect their children.

IV.The function of learning: Several parents consider that it would be better to have some learning functions for children to use, such as reading newspapers, reading electronic books, playing puzzle games and MP3.

\subsection{What Are Children's Opinions of Having Their Own Mobile Phones?}

Most children said that they want to have a mobile phone to play games and keep in touch with parents. Moreover, they can use a mobile phone to help with their homework such as using the calculating function and searching some information on the Internet. b said that "I like to use the calculating function in mobile phones to do my homework and I also like to play games in mobile phones."

\section{Conclusions and Suggestion}

\subsection{Conclusions}

For parents, the main factor that may affect parents buying mobile phones for children is the price of mobile phones. Most parents still think that the price has to be reasonable. Besides, the secondary factor is the functions of mobile phones. Making a phone call can be the most useful function for children to use in parents' opinions. On the other hand, parents also hope that there can be some limit and learning functions for children to use. The remaining purchase factors can be the reception of mobile phones, the brand of mobile phones, mobile phone carriers, promotional activities of mobile phone carriers and the appearance of mobile phones. Besides, the need for the convenience of contact is the crucial motivation that can drive parents to purchase mobile phones for children as the Table 2 . When children really need to use a mobile phone, most parents are willing to buy one for them.

Table 2. Parents'Motivation of Buying Children Mobile Phones.

\begin{tabular}{ll}
\hline Motivation & $\begin{array}{l}\text { Number of parents (total 20 } \\
\text { people) }\end{array}$ \\
\hline The need for the convenience of contact & 20 \\
As a prize for children & 2 \\
\hline
\end{tabular}

Source: this research.

From the findings of this study, there are several functions that parents hope to have in children's mobile phones. Most parents think that some general functions can be very useful for children to use such as making a call and sending a text message. Moreover, some parents hope that there can be some limit functions in mobile phones for children to use, such as the restriction of call duration and the limit of Internet access duration. Some parents also hope that children's mobile phones can have more learning functions. However, there are two main functions that parents don't hope to have in children's mobile phone, including the Internet and the built-in games in mobile phones. Table 3 shows the functions that parents hope to have or not to have in children's mobile phones.

Table 3. Parents' Opinions of the Functions for Children to Use.

\begin{tabular}{ll}
\hline 1. Functions that parents hope to have in & Number of parents (total \\
children's mobile phones & 20 people) \\
General functions & 17 \\
Limit functions setting & 7 \\
The function of Global Positioning System & 4 \\
The function of learning & 3 \\
2. Functions that parents hope not to have in & Number of parents (total \\
children's mobile phones & 20 people) \\
The Internet & 16 \\
Built-in games in mobile phones & 9 \\
\hline
\end{tabular}

Source: this research.

In children's views, they all want to have their own mobile phones. Mobile phones can help them with many things such as contacting parents and friends, doing their homework, and searching some information through the Internet. Moreover, mobile phones also have entertainment value for children. Since the release of smart phones and apps, a lot of games and applications have become very popular. This can be a big attraction to kids. Consequently, most children hope that their parents can buy mobile phones for them, especially smart phones. From the findings of this study, there are five incentives that may make children want to have their own mobile phones as the Table 4. It shows that most children want to have a mobile phone to play games.

Table 4. Children's Motivation of Having Mobile Phones.

\begin{tabular}{ll}
\hline Motivation & Number of children (total 20 people) \\
\hline Playing games & 15 \\
Making a call & 8 \\
Connecting to the Internet & 8 \\
Being affected by friends & 4 \\
A variety of functions & 4 \\
\hline
\end{tabular}

Source: this research.

\subsection{Suggestion}

The first point is that parents care about the price of mobile phones. Therefore, they would like to consider promotional activities of mobile phone carriers to obtain a good value for money. Mobile phone carriers can also promote their products to parents strongly. The next point is that the functions of mobile phones should be simpler for children to use. In addition, parents also hope that mobile phone carriers can set some limit functions and learning functions in children's mobile phones. For example, limit functions can be the restriction of call duration and the limit of Internet access duration. Parents also hope that mobile phone carriers can block bad websites that children may be fascinated unconsciously. Some learning functions can be reading newspapers, reading electronic books, playing puzzle games, using Chinese and English dictionaries, and so on. Children also express that they like to use the calculating function to help them with homework and some basic counting. Moreover, some parents think that the reception of mobile phones is very 
important and they also believe that it is safer for children to use a mobile phone with GPS.

\subsection{Limitation of the Study}

Based on the time and cost considerations, the researcher imposes restrictions on the scope of this study. Due to the region and time limits, the researcher simply focuses on the participants who live in Tainan. The researcher uses the purposive sampling and selects forty respondents, including twenty pairs of parents and children. Hence, the results of this study are only based on the contents from all interviews. It could not be a national survey. Besides, due to the ability of expression and comprehension, the researcher decides to select the fifth and sixth grade students as interview subjects. The researcher will mainly collect information from the interviews with the fifth and sixth grade students. Thus, there is no way to know children's opinions of mobile phones from other grades.

\section{References}

[1] Wang, HY, Liao, C., and Yang, L-H (2013). What Affects Mobile Application Use? The Roles of Consumption Values. International Journal of Marketing Studies, 5(2), 1918-7203.

[2] GSM Association \& Mobile Society Research Institute, Task Force on Children's Use of Mobile Phones. (2013). Children's Use of Mobile Phones-An international comparison 2012. Retrieved from http://www.gsma.com/publicpolicy/wp-content/uploads/2012/ 03/GSMA_ChildrensMobilePhones2012WEB.pdf.

[3] Foreseeing Innovative New Digi services. (2010). Smartphone users become the key group due to mobile phone services promoting from the communication to the data. Retrieved from http://www.find.org.tw/find/home.aspx?page=news\&id=5800.

[4] Devitt, K., \&Roker, D. (2009). The Role of Mobile Phones in Family Communication. Journal of Children and Society, 23(3), 189-202. doi:10.1111/j.1099-0860.2008.00166.x.

[5] Child Welfare League Foundation, Task Force on The Survey of Children's Uses of Mobile Phones in Taiwan. (2011). The Survey of Children's Uses of Mobile Phones in Taiwan. Retrieved from http://www.children.org.tw/old_site/news.php?id=2593.

[6] Navarro, V., \&Rakow, L. F. (1993). Remote Mothering and the Parallel Shift: Women Meet the Cellular Telephone. Critical Studies in Media Communication,10(2), 144-157.

[7] Lee, S., Tam, C. L., \& Chie, Q. T. (2014). Mobile Phone Usage Preferences: The Contributing Factors of Personality, Social Anxiety and Loneliness. Social Indicators Research, 118(3), 1205-1228.

[8] Acuff, D. S., \&Reiher, R. H. (1997). What Kids Buy and Why: The Psychology of Marketing to Kids. New York, NY: Free Press.

[9] Chiang, H. S., \& Hsiao, K. L. (2015). YouTube stickiness: The needs, personal, and environmental perspective. Internet Research, 25(1), 85-106.

[10] Cheng, B. S. (1994). Consumer Psychology. Taipei, Taiwan: DaYang Publishing Company.
[11] Guiltinan, J. P. (1999). Launch Strategy, Launch Tactics, and Demand Outcomes. Journal Product Innovation Management, $16,509-529$.

[12] Armstrong, G., \& Kotler, P. (2001). Principles of marketing. $\left(9^{\text {th }}\right.$ ed.). New Jersey: Prentice-Hall.

[13] Kao, K. E.(2004). A Study on Market Segmentation of Taipei Region Consumer of Willingness to Accept Smart Phone-An Innovation Adoption Process Approach. National Chiao Tung University: Hsinchu, Taiwan.

[14] Huang, P. J. (2004). A Study of Market Segmentation of Mobile Photography Consumer and Their Perception and Preference. National Taipei University: Taipei, Taiwan.

[15] Lai, C.-H., \&Gwung, H.-L. (2013). The effect of gender and Internet usage on physical and cyber interpersonal relationships. Computers \& Education, 69, 303-309.

[16] Chang, T. M., Chen, S. J., Hsieh, C. S., Hsing, J. W., Lee, M. C., Liao, J. Y., \& Wang, F. L. (2008). The Study of Purchase Motivation, Satisfaction, and Loyalty for College Students to Purchase Mobile Phones: A Case of Students at Hsiuping Institute of Technology. Hsiuping Journal, 16, 21-40.

[17] Insight Xplorer Limited, Task Force on The Survey of the Situation of Mobile Phone Usage in Taiwan.(2005). The Survey of the Situation of Mobile Phone Usage in Taiwan. Retrieved fromhttp://www.insightxplorer.com/specialtopic/self_mobile2 0060126 2.html.

[18] Lan, S. T. (2011). A Study of the Influence on Repurchase Intention of Purchase Motivation and Customer SatisfactionThe Bicycle Industry for Example. I-Shou University: Kaohsiung, Taiwan.

[19] Christensen, C. M. (2000). The Innovator's Dilemma: When New Technologies Cause Great Firms to Fail Boston, MA: Harvard Business School Press.

[20] Pei, P. I. (2004). The Study of Purchase Motivations in TV Shopping Channel. National Cheng Kung University: Tainan, Taiwan.

[21] Wang, H., Gu, G., An, S., \& Zhou, G. (2014). Understanding Online Consumer Stickiness in E-commerce Environment: A Relationship Formation Model. International Journal of u-and e-Service, Science and Technology, 7(3), 151-162.

[22] Tsai, K. C. (2005). A Study on Purchasing Decision of Domestic Readers of Best-Sellers (Unpublished master's thesis). Nanhua University: Chiayi, Taiwan.

[23] Chiu, H. H. (2009). The Study of Purchasing Behavior in Selecting Male Facial Skin Care Products From Female Consumers. Chaoyang University of Technology: Taichung, Taiwan.

[24] Hsu, C. M. (2011). A Study on Generation Y Consumer Purchase Motivation and Conspicuous Value for NBA Star Endorsement Shoes. National Taiwan Normal University: Taipei, Taiwan.

[25] Chung, T. L. (2012). A study on purchase motivation, involvement and consumer behavior: An investigation into consumers of bubble tea. Southern Taiwan University of Science and Technology: Tainan, Taiwan.

[26] De Meulenaere, J., Bleumers, L., \& Van den Broeck, W. (2015). An audience perspective on the 2 nd screen phenomenon. The Journal of Media Innovations, 2(2), 6-22. 
[27] Assael, H. (1998). Consumer Behavior and Marketing Action. ( $6^{\text {th }}$ ed.). Ohio: South-Western College Publishing.

[28] Diehl, D. C., Guion, L. A., \& McDonald, D. (2011). Conducting an In-depth Interview. Retrieved from http://edis.ifas.ufl.edu/fy393.

[29] Boyce, C., \& Neale, P. (2006). Conducting In-Depth Interviews: A Guide for Designing and Conducting In-Depth Interviews for Evaluation Input. Watertown, MA: Pathfinder International.
[30] Dominick, J. R., \& Wimmer, R. D. (2006). Mass Media Research: An Introduction. ( $8^{\text {th }}$ ed.). Belmont, CA: Wadsworth Publishing Company.

[31] Babbie, E. R. (1998). The Practice of Social Research. Belmont, CA: Wadsworth Publishing Company.

[32] Tashakkori, A., \&Teddlie, C. (2003). Handbook of Mixed Methods in Social \&Behavioral Research. Thousand Oaks, CA: Sage Publications. 